\title{
Investigating the Effect of Inflation Disclosure on Improving the Information Content of the Financial Reporting
}

\author{
Vali khodadadi ${ }^{1}$, Ali Vaez ${ }^{1} \&$ Hashem Alisufi ${ }^{1}$ \\ ${ }^{1}$ Department of Accounting, College of Economics and Social Sciences, Shahid Chamran University of Ahwaz, Iran \\ Correspondence: Hashem Alisufi, Department of Accounting, College of Economics and Social Sciences, Shahid \\ Chamran University of Ahwaz, Iran. Tel: 98-915-522-8729. E-mail: hashemalisufi@gmail.com
}

Received: April 5, 2014

Accepted: May 11, 2014

Online Published: June 3, 2014

doi:10.5430/ijfr.v5n3p96

URL: http://dx.doi.org/10.5430/ijfr.v5n3p96

\begin{abstract}
This study aims to investigate the inflation disclosure on improving the information content of the financial reporting of the accepted companies in the Tehran stock exchange market. To investigate this issue three hypotheses were provided and tested. To this aim, 120 accepted companies' data in the Tehran stock exchange was analyzed using the data panel method with fix effects during 2002 to 2012. General results showed that inflation does not have a significant effect on the information content of the financial reporting of the companies in Tehran stock exchange. Specifically, the results of the first hypothesis showed that there is no significant difference between the information content of modified accounting earnings and the inflation effects compared with the reported accounting earnings in prediction of operating cash flow. The results of the second hypothesis showed that there is not either a significant difference between the modified accounting earnings information content and the inflation effects compared with the reported accounting earnings in prediction of stock return. The results of the third hypothesis also showed that there is not a significant difference between the modified accounting earnings information content and the inflation effects compared with the reported accounting earnings in prediction of abnormal return.
\end{abstract}

Keywords: inflation, information content of financial reporting, monetary items, non-monetary items

\section{Introduction}

According to the accounting standards, one of the objectives of the financial statements is to present brief and classified information about the financial status, financial performance, and financial flexibility of the business unit that can be useful for a wide range of financial statements' users in economic decision making (Technical Committee of Audit Organization, 2003). Based on the theoretical accounting framework, the presented information by the accounting system should have three features of being relevant, being in time, and being reliable (Saghafi, 1997). According to this principle, all of the properties should be recorded according to finished cost and the historical values should be used as a basis for information provision for users (Malekian, 1996). The more and more useful the information content of the financial reporting, the more logical utilization of the financial reporting for more logical decision making will be. This leads to the optimized dedicating of resources and the economic growth and development (Accounting Standards Board, 1984).

Wolk et al (1992) believe that the financial reports should provide the decision makers with useful information, i.e. the relevant and reliable, in time, complete, and understandable information about the financial events of the business unit with the least expenses. The main issue in accounting is presenting the useful information which should be described in relation with users of accounting system and it is a role that accounting is trying to play with its new concepts and domains. Novin (1982) thinks if the "accuracy" means impartial, fair, without any changes reporting and transferring of information and events, the accounting will turn into a medium that is responsible for reflecting all of the information and events. In other words, it should reflect what the accounting system accepts, not change the process of accepting the events and information processing, present and reflect them in accordance with the common accounting definition accurately.

According to the first proclamation of Financial Accounting Standards Committee, the comparison capability is also one of the qualitative features of accounting information (Accounting Standards Board, 1978), but combining the currency units ins different periods with different values has decreased the information comparison capability of one 
company during the time periods. The measuring unit in accounting assumes the purchasing power of money as permanent, while during the periods with low inflation and even lower prices this hypothesis is rejected.

Several years have been passed from the time of proposing the subject of inflation effects on accounting in general, and on financial statements in particular. Despite of the existence of high inflation rate in Iran, and the belief of the most users of financial statements, economic decision makers, and specifically managers towards the uselessness of accounting information compared with the day prices, and also the presence of professional accounting organizations and its importance as an academic subject, the issue of inflation effects on accounting has not been concerned as an important matter to be executed and researched (Royaei, 1993). On the other hand, the relevant state organizations and agencies and the stock exchange organization have not felt the need to enter into this field of accounting; accordingly, the outcomes of this issue have not been investigated extensively.

According to the accounting theories, observing the market response to the accounting variables provided the theorists the guidelines to evaluate the information content of the accounting data and choosing a better criterion to predict the business event (Dechow, 1995). Thus, the behavior test of the securities and accounting data will be used as a criterion to evaluate the usefulness and the quality of the accounting information.

On the other hand, the issue of inflation effects on the accounting information and financial statements have theoretically had attractive and challenging image. Investigating the thoughts and ideas evolution direction on the one hand and the permanent and serious attempts by the professional institutes in other countries on the other hand are considerable issues. Yet, the pleasant aspects of the debates, con or pro ideas dynamically based on the openness of the accounting system, and the adaptability feature to the environmental conditions have given off this profession.

Inflation causes the distribution of properties and incomes. People whose properties' value has increased more than the inflation rate will get use of the inflation and those with less value for their properties will suffer. Accordingly, the economic activists who cannot increase their nominal incomes at the level of inflation due to legal limitations will suffer. By investigating the inflation effects, it is concluded that those types of companies accepted in the stock exchange which have properties being affected much more by the inflation, the inflation effects on increasing their shares' prices are also the same. As a result, shares are acceptable for the individuals, because any shareholder receives a share equal to their own share sheet from the company and expect the price rate increasing for their own shares with increasing the company's properties value increasing. Therefore, those shareholders with their nominal shares' return increasing more than the inflation rate will get benefits and the others with lower growth compared with the inflation rate will be suffered (Pashaei \& Omidipour, 2010).

Thus, in order to examine the financial reporting quality, in this research the necessity of this hypothesis that the earnings' (losses') information resulted from inflation can assist the users to progress for better prediction about the future cash flow and the shares' return has been noticed. Although the effects of inflation on the financial reporting during the 1970s were noticed remarkably when the inflation rate was double-digit, they were forgotten after decreasing. Nowadays, the analytic, financial, and tax reporting are according to nominal values, the current financial statements, earnings and losses resulted from the purchasing money power are not calculated and reported. For instance, the decreasing of properties' value resulted from the inflation is considered as loss for companies, whereas the decreasing of company's debts value resulted from the inflation are considered as benefit (Konchitchki, 2011). In this study regarding the inflation effects on the accounting earnings and modification of financial statements are the hypotheses.

\section{Theoretical Foundations}

The committee of accounting procedure in 1961 and the accounting research development in 1963 investigated the effect of prices level changing issue. Although the modification based on the general level changings of the prices had not been requested by accounting principles board, the mentioned committee has supported the usage of modified financial statements as the annex or the appendix information in its third research with the title of "Modified financial reporting according to prices' general level" published in 1969. In this way, the companies can disclosure this information on the condition that it will not be used as the main statements (Accounting Principles' Board, 1961). In 1974, the Board of Financial Standards Accounting published the draft of "financial reporting in form of public purchasing power units" which almost followed the third research of the Accounting principles' board, i.e. the modified financial reporting according to the prices general level. In the same years, when the discussion of modifying or not modifying was still new and interesting, two paradoxical articles were written still counted as the important historical resources for this issue. One of them by Rosenfield, and the other by Audit Institute of "Ernest and Ernest", and both of them attracted the attention of public thoughts and fans' responses. Rosenfield's article (1975) supported the attempt of accounting standards board which was a positive step towards the financial reporting 
improvement; while the stand of the Ernest and Ernest (1975) article was based on this issue that because of some reasons like interfering of a number of noncash and credit expenses (the company's debts) in computing the net earnings the executive expenses related to these modifications and the lack of public demand for the modified financial statements, modification implementation is considered as ineffective. Finally, on February $15^{\text {th }} 1974$, the financial accounting standards' board declared the relevant issue as "it is essential that the effects related to the prices general level changings to be reported as the information with historical financial statements."

According to common methods of accounting, the incomes difference and expenses are as the finished prices. Thus, with permanent prices increasing, a part of the reported earnings by the business firms is related to the goods and products keeping and all of it is considered as the dividable earnings.

To specify the inflation effects and prevent the users and financial analysts' confusion the earnings are divided into two operational earnings and the earnings resulted from the goods keeping. Operational earnings means the income difference and related expenses to the current prices, and goods keeping earnings means the earnings resulted from the company's properties' value increasing that has been obtained as a consequence of prices increasing.

It is clear that in conditions where the prices do not change, there are no earnings resulted from keeping the goods and the calculated earnings according to the finished price are equal to the operational earnings, but in case of rapid and permanent increasing of prices, the earnings from the goods keeping is increased remarkably and can form a huge proportion of the company's earnings. In such conditions, considering the whole company's earnings dividable is delusive and could have harmful outcomes for the shareholders; accordingly, the company's activity continuation in future will encounter the lack of liquidity.

Moreover, companies' tax debts are calculable and payable based on the expressive earnings. Therefore, in inflation conditions a payable part of companies' taxes is related to the earnings resulted from the goods keeping which has not usually come true. Consequently, the companies' lack of liquidity is being intensified largely, and this increases the company's need to the banking, credit, and other external resources firms more than ever.

Using the provided financial statements according to the historical accounting values will have adverse effects on decision making related to the investment in different projects, financial resources dedication in investment market, and also the evaluation of different companies activities in addition to the aforementioned shortcomings. In inflation conditions, using the finished accounting price the return of those company's activities more affected by inflation factors is very higher than the return of other activities. Even if the return of the compared activities was identical in permanent prices conditions, deciding based on different investments' return calculated according to the common accounting method causes increasing the investments in activities that suffered from more inflation conditions in the past. Thus, in case of not continuing the relative prices trend in future the, company's managers will invest adversely regarding the shareholders' interests.

One of the factors that individuals and firms consider during decision making to determine the favorite combination of their investments is the information content of the provided financial statements based on the accounting system. Since the expressive earnings and the companies' balance sheet are not identically affected by prices increasing factors, dedicating the financial resources in investment market is not done favorably and the shares of companies are welcomed more affected by the inflation effects. On the other hand, if the evaluation of different companies' performance to determine the credit policy by the banks or tax policies, support, and pricing are aimed, the rate of companies' earnings, because of the above-mentioned reasons, is not necessarily considered as their economic success or failure.

To obviate the aforementioned shortcomings, the new accounting methods have been suggested. The current purchasing power and current value accounting are the most important methods have been presented to solve the accounting problems in inflation conditions and against the related issued to the inflation reflection in financial statements so far.

These two suggested methods caused a lot of arguments in Anglo Saxon countries and caused the state organizations of these countries to pay especial attention to this issue.

In 1974, England set a commission as the responsible for handling the accounting affairs. This commission presented its comprehensive and detailed report on this issue in 1975 to the government. The commission rejected the professional accountants' suggested associations which were established based on the current accounting purchasing power, and recommended the current accounting approach which was principally confirmed by the professional accountants' association; however, the details have not been confirmed yet totally. 


\section{Review of the Literature}

In a research, Sung (1980) investigated the effects of modified accounting information disclosure based on the prices index. In fact, he intended to investigate the response of the shares' price to the modified information base on the existed theories. The results of his study showed that with modified information disclosure the shares' return had increased simultaneously. However, this fact is true about the large and medium companies and not about the small ones. In addition, the rate of being affected of various industries by the modified information is different. In other words, the market has responded to this information.

Gregory et al (2005) found that the stability of the unusual earnings elements provided by the basis of finished historical price is not comparable statistically with the stability of the unusual earnings elements modified based on the inflation rate.

Ashton et al (2010) investigated the effect of historical finished price under the inflation pressure on the residual income. They found that inflation does not affect the structure of the residual income. Also, it was found that even if there is no intense inflation, the value of many items is evaluated less than their real value.

Garmendia (2010) investigated the short-term effects of inflation on the shares prices, earnings, and leverage. The obtained results of this study showed that 1) inflation has e negative relationship with the companies' real earnings and the amount of this relationship depends on the inflation rate, 2) imposing the leverage into the models causes the modification and verification of this relationship, and 3) there is a positive significant relationship between individuals' risk aversion and inflation.

Boudoukh and Richardson (1993) investigated the relationship between inflation and shares return in short-term (one year) and long-term (5 years) periods. They examined the long-term annual data in the U.S and Britain. The results showed that there is almost no relationship between the inflation and nominal earnings of the shares in short-term (one year) period, whereas in long-term (5 years) period the Fischer's equation is correct and this relationship is positive.

In 2009, Kirkulak and Balsari found that the earnings and book value are effective remarkably both based on the historical finished prices and the modified one about the inflation. Also, Anandarajan et al (2006) found that the modified data about the inflation has strong correlation with the investment market value. Fama (1981) tried to explain the unsual relationship between inflation and shares return. His hypothesis was that the observed negative relationship between the shares real return and inflation in the period after 1980 was resulted from the chain effects. His explanations were against the Philips' first curve hypothesis, i.e. there was a negative correlation between inflation and economic activity. On the other hand, the relationship between the real activity and shares' return is positive. The negative correlation between the shares' real return and inflation is called the chain effects because of the link of these two relationships.

In 1990, Hernandez investigated the relationship between the shares' real return and inflation in the 60s, 70s, and 80s using the chain effect hypothesis and found that there was no significant relationship between these two variables in two periods among the three ones.

Onro (1996) examined the relationship between the shares' real return and inflation for six industrial countries during 1976 to 1992 using the chain effect. The results of this study showed that there would be a negative relationship between the shares' real return and inflation rate even after modifying the expected economic activities effects and inflation fluctuations. Thus, the findings of this study confirm the chain effect hypothesis.

Graham (1996) studied the relationship between the shares' real return and inflation in the United States of America using the information of the post-world war II. He found that this relationship was instable, i.e. the relationship between the shares' real return and inflation before 1976 and after 1982 is negative, but there is a positive relationship during 1976 to 1981.

In an article, Azizi (2005) experimentally investigated the relationship between the inflation and shares' return in Tehran securities exchange. In this article the monthly inflation data, cash return, total return (cash and price), and the shares' price index were used during 1999 to 2004, and using the VAR method and Granger causality test the relationship between these variables was tested quantitatively. The obtained results based on the VAR model showed that the inflation explains the cash return index and total return (price and cash), but does not explain the shares price index. On the other hand, the cash return, total return (cash and price), and the shares price index do not explain the inflation. These findings as well as the results obtained from the Granger causality test about the price return, cash return, price, and shares price index were confirmed. Shariatpanahi and Bayati (2006) studied the relationship between inflation and shares price index and cash return in Tehran securities exchange. To this aim, the monthly data 
during 1991 to 2005 was used. The data analysis showed that investing in Tehran securities exchange cannot be a good shield against the inflation.

Sameti and Moradian (2008) examined the relationship between the company's value and inflation rate using the Tobin Q index during 1995 to 2005. The results of their study indicated that either through the Pearson correlational coefficient or the regression test, there was no significant relationship between the Tobin Q proportion and inflation rate. At the same time, when the regression was implemented individually for each company during the mentioned time period, the results indicated the inflation effect on ten companies' value.

Bhatnagar and Kumar (2012) examine the impact of inflation on financial reporting in companies engaged in the Delhi Stock Exchange. Their results show that firms in the high inflation economy pay a lot of taxes fees and this issue in long-term have negative impact on their capital and investment.

In a research, Dastgir and Omidali (2005) investigated the reasons of not applying the inflation accounting. The results of their study showed that the reasons of not applying the inflation accounting in Iran are: serious unfamiliarity of the managers with inflation accounting, insufficient promotion prices index, increasing the tax debts resulted from the re-evaluation, increasing the inflation accounting cost over its income, and lack of government support towards the inflation accounting.

\section{Research Hypotheses}

It is hypothesized in this research that if a company's activities, regardless how are reported in financial statements, do not disclose the earnings or losses resulted from inflation, the inflation effects will be revealed in next periods. Regarding this fact that the date of each event is not presented in information financial statement and the events are reported in time-periods when the currency value is not stable, there is a lack of information disclosure. To present the extra information according to the measuring unit, the items of financial statements do not include the earnings and losses from inflation. In addition to this financial reporting, the inflation effects on non-monetary items including the observable permanent properties are not reported. With respect to this issue that the average life-time of the properties and debts is more than one year, the inflation is expected to be effective on the companies' financial reporting; accordingly, the research hypotheses are as following:

First hypothesis: compared with the accounting earnings, the modified earnings, considering the inflation effects, have more information content in predicting the future operating cash flow.

Second Hypothesis: compared with the accounting earnings, the modified earnings, considering the inflation effects, have more information content in predicting the stock' return.

First peripheral hypothesis: compared with the accounting earnings, the modified earnings, considering the inflation effects, have more information content in predicting the return.

Second peripheral hypothesis: compared with the accounting earnings, the modified earnings, considering the inflation effects, have more information content in predicting the abnormal return.

\section{Research Methodology}

The method in this research is the type of quasi-experimental. In these types of studies, the researcher does not have any control over the data creating. The required data in this research which is the result of different existed processes in companies and exchanging process in securities exchanges is collected from information banks, and then the research hypotheses are tested using the mentioned data. On the other side, the present study is a type of proving research in which the researcher is looking for what it is and no prescription is suggested, but regarding the research results some recommendations are presented.

\subsection{Hypotheses Testing}

In this study, in order to calculate the earnings or losses resulted from inflation of the non-monetary items of the financial statements an algorithm was applied which following three important stages extract the real information. In the first stage of this algorithm, the financial statements during the whole company's life are re-established based on a regulated basis according to inflation. In the second stage, since distinguishing between the monetary and non-monetary items is a key to this issue that how the accounting amounts are affected by inflation differently, this algorithm separates the properties, monetary, non-monetary commitments. Since the monetary items under the nominal reporting of the settlement amount or turning it to the cash is equal with the values reflected in financial statements, thus in this algorithm the monetary amounts of the nominal financial statements are not used. In contrasts, the third stage regulates the non-monetary items estimating the purchasing date using the life-time periods, the times of goods flow and etc. In this research, because of the following reasons the modified values based on inflation are 
used instead of current values: a) the reliability and objectivity of the market values are little due to their estimating, b) all of the non-monetary items do not have the observable market values and an appropriate pricing system cannot be available for second-handed properties. The values modification approach based on inflation is more objective because it is measured according to a price index which cannot be affected by the companies. However, it is possible that in comparison with current values it has less accuracy, because the weights should be dedicated to the regulatory index are different cross different companies.

To use the aforementioned algorithm, first the monetary and non-monetary items are separated, and then during some stages the nominal information will be turned into real values.

In order to test the capability of earnings and losses of inflation to predict the next cash flows, the operations of CFO, extended Barth framework, Cram and Nelson (2001) are used. It is predicted that adding the inflation modified earnings and losses to the predictor equation of BCN will increase the capability of CFO's prediction; accordingly, the following equation is obtained:

\section{First model:}

$$
\mathrm{CFO}_{\mathrm{t}+1}=\alpha+\beta_{\mathrm{RMN}} \mathrm{RMN}_{\mathrm{t}}+\gamma_{1} \mathrm{CFO}_{\mathrm{t}}+\gamma_{2} \Delta \mathrm{AR}_{\mathrm{t}}+\gamma_{3} \Delta \mathrm{INV}_{\mathrm{t}}+\gamma_{4} \Delta \mathrm{AP}_{\mathrm{t}}+\gamma_{5} \mathrm{DEPN}_{\mathrm{t}}+\gamma_{6} \mathrm{OTHER}_{\mathrm{t}}+\gamma_{7} \mathrm{CG}_{\mathrm{t}}+€_{\mathrm{t}+1}
$$

\section{Second model:}

$$
C F O_{t+1}=\alpha+\beta E_{t}+\gamma_{1} C F O_{t}+\gamma_{2} \Delta A R_{t}+\gamma_{3} \Delta I N V_{t}+\gamma_{4} \Delta A P_{t}+\gamma_{5} D E P N_{t}+\gamma_{6} O_{T H E R}+\gamma_{7} C G_{t}+\epsilon_{t+1}
$$

where $C F O_{t}, A R_{t}, I N V_{t}, A P_{t}, D E P N_{t}, O T H E R_{t}$, and $C G_{2}$ are indicating the operational cash flows, received accounts, inventories, payment accounts, depreciation of permanent properties, depreciation of unobservable properties, other commitment items are the functions of time and the company's dominancy; $\Delta$ indicates the $t$ to $t+1$, and $R M N$ equals to the real earnings. $E$ is equal to the reported earnings from the loss and earning statement. For each year the equation is estimated from the following 4 years, i.e. $i=1$ to 4 .

To calculate the company's dominancy the variables like ownership concentration, institutional ownership, management ownership, and managers independence were used.

In order to investigate the explaining power and the information content of the real earnings the modified $R^{2}$ of the above models have been compared and also to investigate the difference between these two $R^{2}$ to be significant the Wang $Z$ test is used. Furthermore, to investigate if entering the real earnings lead to improving the ability of predicting the operational cash, the mean absolute percent error (MAPE) is applied.

The real earnings of year $t$ are calculated according to the following method (Konchitchki, 2009):

The real earnings $s_{t}$ - (accumulated modified earnings $s_{t}$-accumulated modified earnings $\mathrm{s}_{\mathrm{t}-1^{-}}$other effective items on accumulated earnings without direct effect on the net earnings $\mathrm{s}_{\mathrm{t}}$.

\section{Modified retained earnings in year t:}

The modified retained earnings in year $t$ is obtained in form of the remaining construction by contribution of $t$-year-balance-sheet. Since the monetary items of year $t$ have been expressed, there is no need to modification. The way of modifying each of the items of balance sheet to obtain the modified retained earnings in year $t$ is as following:

\section{Non-monetary items:}

These items are the items which keep their purchase power over time and their price will change based on the monetary changes compared with the general prices level or specific prices.

\section{A) Plants, properties and equipment (PPE)}

For each company is calculated regarding to depreciation of the properties' life cycle.

Properties' life cycle $-\frac{1}{n} \sum_{i}^{t}=t-n+1\left[\frac{\text { gorss property }}{\text { depreciation }}\right.$

And then these properties are modified as following:

The net PPE $\times \frac{\text { CPI (consumer price index the end of the year }}{\text { CPI of the last month }(12 \times 0.5 \times \text { property life cycle })}$

It is assumed that the companies use the direct line method to their properties depreciation.

\section{B) Inventories}

To modify the balance of the inventory turnover ratio (the number of times the inventory has been sold and substituted) is used. This ratio is equal to the finished price of the sold goods divided by the inventory. To prevent 
the negative effect of the sudden changes of the inventory in a period on the results the balance end of the period of two consecutive periods is used. Because the selling is based on the current value and the inventory is usually priced based on the finished price the value of the sold goods finished price is used. For example, if the inventory divided by cost of sold goods is equal to 2, i.e. the inventory has two turnovers a year and the balance of the inventory period is 6 months. Accordingly, the life of the end period inventories is 3 months and they are modified as following:

$\mathrm{IT}=\mathrm{Cycle} I N V \times \frac{\text { end of year } C P I}{\text { CPI of last month }\left(0.5 \times \frac{12}{T T}\right)}-(I N V)$ modified inventory

Since the real and nominal incomes are obtained from the subtraction between the accumulated earnings of two consecutive periods (which are adapted with the shares earnings and investment changes), these items should be excluded from the accumulated modified earnings when obtaining the modified revenues.

\section{C) Other properties}

Other properties $_{t}-$ sum of the properties $s_{t}-$ inventory $_{t}-$ net permanent evident properties $s_{t}$

* It is assumed that other properties belong to the monetary items (Konchitchki, 2009).

\section{D) Common stocks and stock premium}

To modify this part, the common stocks and stock premium have been divided into two parts. The first layer includes all of the company's stocks publishing from the time of its foundation to the end of year $\mathrm{t}-1$, and the second layer includes the publishing of stocks during year $t$.

\section{First layer}

Modified common stocks and stock premium $\mathrm{t}_{\mathrm{t}}=(\text { common stocks and stock premium })_{\mathrm{t}-1} \times$ consumer price index at the end of the year $r_{t} /$ consumer price index in 12 months before the end of the year ${ }_{t}$

\section{Second layer}

It is assumed that the new publishing during the year have occurred identically (Konchitchki, 2009). Thus, the publishing has been modified with the consumer price index balance year.

New modified publishing of year $r_{t}=\left[(\text { common stocks }+ \text { common stock premium })_{t}-(\right.$ common stock + common stock

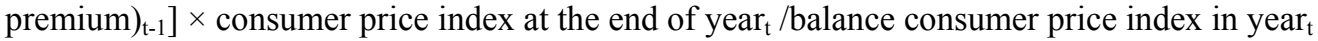

E) Other monetary items of the shareholders right except for the retained earnings are calculated as following:

Other monetary items of the shareholders right except for the retained earnings $s_{t}=$ total $_{\text {assets }}-$ total debts $_{t}-$ retained earnings $\mathrm{s}_{\mathrm{t}}-$ common stocks $_{\mathrm{t}}-$ common stock premium $_{\mathrm{t}}$

The modified retained earnings of the year $t$ are obtained as following:

The modified retained earnings of the year $r_{t}=$ modified inventories of the year ${ }_{t}+$ net permanent evident properties of the year $r_{t}+$ other properties of year $r_{t}+$ common stocks and modified common stocks premium $t+$ modified new publishing $_{t}+$ other monetary rights of the shareholders except for the retained earnings $s_{t}+$ total debts $_{t}$

In this equation other properties, total debts, and other monetary items of the shareholders rights except for the retained earnings are considered as monetary items.

\section{Modified retained earnings in year t-1}

The modified retained earnings in year $\mathrm{t}-1$ are calculated with a similar method to the modified retained earnings in year $t$. However, it differs in this fact that in calculating the modified retained earnings of the year $\mathrm{t}-1$ the monetary inventories in balance sheet of the year $\mathrm{t}-1$ are also modified to the money of the equation in year $\mathrm{t}$ in addition to monetary items (Konchitchki, 2009).

Modified monetary item $=$ monetary item $\times$ (inflation index at the end of the year ${ }_{t} /$ inflation index at the end of the year $\left.{ }_{t-1}\right)$

Modified EPS: the third element of the real earnings' equation is the common shares' earnings which are added in order to eliminate the other effective factors on the accumulated earnings' changes of that year--with this assumption that the common shares' earnings are identically distributed during the year (Konchitchki, 2009).

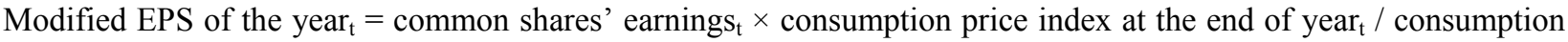
price index balance of the year ${ }_{t}$ 


\section{Other items effective on the retained earnings without direct effect on net earnings:}

According to the applied algorithm, these events occur at the end of year t. Thus, they are treated as done to monetary items. Since these items are among the monetary items existed in the balance sheet of the year $t$, there is no need to inflation modification (Konchitchki, 2009).

Other items effective on the accumulated earnings without direct effect on the net earnings $=$ retained earnings $\mathrm{t}_{\mathrm{t}}-$

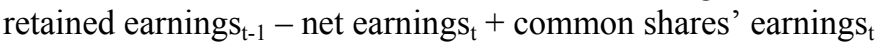

In the second hypothesis the information content of the inflation modified earnings in predicting the shares' return has been investigated. This hypothesis is investigated from two viewpoints.

In the first viewpoint, the information content of the inflation modified earnings in predicting the shares' common return has been investigated. In the second viewpoint, the information content of the inflation modified earnings in predicting the unusual share return has been investigated. In order to calculate the unusual shares' return the modified market model has been used. In this model it has been hypothesized that the market return is the result of expected process of the companies' shares return in any period. Therefore, the difference of the real return of the company $i$ in time period $t$ with the market return at the same period indicates the unusual return of the shares of company $i$ in period of $t$.

$$
\begin{gathered}
a r_{i t}=r_{i t}-r m_{t} \\
r m_{t}=\left(I m_{t}-\operatorname{Im}_{0}\right) / I m_{o} \\
A r_{t}=1 / N \Sigma a r_{i t} \\
C A R_{t}=\Sigma A R_{t}
\end{gathered}
$$

$r_{i t}$ is equal to the return rate of shares $i$ in month $t$

$r m_{t}$ is equal to the return rate of market shares $i$ in month $t$

$a r_{i t}$ is equal to unusual return of shares $i$ in month $t$

$I m_{t}$ is equal to total index of the stock at the end of month $t$

$I m_{0}$ is equal to total index of the stock at the beginning of $t$

$A r_{t}$ is equal to the average rate of return of $n$ shares in month $t$

$C A R_{t}$ is equal to unusual return of the accumulative return of the shares

The second hypothesis has been tested through the regression models including the capabilities of inflation modified earnings in predicting the normal and abnormal return. The third and fourth models are used in predicting the return, fifth and sixth models in predicting the abnormal return of the shares.

\section{Third model}

$$
\mathrm{R}_{\mathrm{t}+1}=\alpha+\beta_{\mathrm{RMN}} \mathrm{RMN}_{\mathrm{t}}+\gamma_{1} \mathrm{CFO}_{\mathrm{t}}+\gamma_{2} \Delta \mathrm{AR}_{\mathrm{t}}+\gamma_{3} \Delta \mathrm{INV}_{\mathrm{t}}+\gamma_{4} \Delta \mathrm{AP}_{\mathrm{t}}+\gamma_{5} \mathrm{DEPN}_{\mathrm{t}}+\gamma_{6} \mathrm{OTHER}_{\mathrm{t}}+\gamma_{7} \mathrm{CG}_{\mathrm{t}}+\epsilon_{\mathrm{t}+1}
$$

\section{Fourth model}

$$
\mathrm{R}_{\mathrm{t}+1}=\alpha+\beta \mathrm{E}_{\mathrm{t}}+\gamma_{1} \mathrm{CFO}_{\mathrm{t}}+\gamma_{2} \Delta \mathrm{AR}_{\mathrm{t}}+\gamma_{3} \Delta \mathrm{INV}_{\mathrm{t}}+\gamma_{4} \Delta \mathrm{AP}_{\mathrm{t}}+\gamma_{5} \mathrm{DEPN}_{\mathrm{t}}+\gamma_{6} \mathrm{OTHER}_{\mathrm{t}}+\gamma_{7} \mathrm{CG}_{\mathrm{t}}+\epsilon_{\mathrm{t}+1}
$$

Fifth model

$$
\mathrm{CAR}_{\mathrm{t}+1}=\alpha+\beta_{\mathrm{RMN}} \mathrm{RMN}_{\mathrm{t}}+\gamma_{1} \mathrm{CFO}_{\mathrm{t}}+\gamma_{2} \Delta \mathrm{AR}_{\mathrm{t}}+\gamma_{3} \Delta \mathrm{INV}_{\mathrm{t}}+\gamma_{4} \Delta \mathrm{AP}_{\mathrm{t}}+\gamma_{5} \mathrm{DEPN}_{\mathrm{t}}+\gamma_{6} \mathrm{OTHER}_{\mathrm{t}}+\gamma_{7} \mathrm{CG}_{\mathrm{t}}+\epsilon_{\mathrm{t}+1}
$$

\section{Sixth model}

$$
\mathrm{CAR}_{\mathrm{t}+1}=\alpha \beta \mathrm{E}_{\mathrm{t}}+\gamma_{1} \mathrm{CFO}_{\mathrm{t}}+\gamma_{2} \Delta \mathrm{AR}_{\mathrm{t}}+\gamma_{3} \Delta \mathrm{INV}_{\mathrm{t}}+\gamma_{4} \Delta \mathrm{AP}_{\mathrm{t}}+\gamma_{5} \mathrm{DEPN}_{\mathrm{t}}+\gamma_{6} \mathrm{OTHER}_{\mathrm{t}}+\gamma_{7} \mathrm{CG}_{\mathrm{t}}+\epsilon_{\mathrm{t}+1}
$$

In this research the quantitative methods include the descriptive statistics and regression analysis used to analyze the applied data according to the mentioned statistical techniques. The descriptive statistics provides a series of primary outlined data on the basic features of the samples. The correlational analysis is used to test the relationship between the independent and dependent variables fundamentally. In all of the statistical techniques the Eviews software is used.

\section{Results}

Descriptive statistics

In the following table a general profile of the used data in the research is illustrated. 
Table 1. Descriptive statistics

\begin{tabular}{cccccc}
\hline variable & mean & median & maximum & minimum & S.D. \\
\hline Operational cash flow & 0.138 & 0.111 & 0.879 & -0.384 & 0.163 \\
\hline abnormal return & 0.022 & -0.04 & 3.84 & -1.84 & 0.82 \\
\hline Return & 0.31 & 0.125 & 3.42 & -0.795 & 0.699 \\
\hline Payable accounts & 0.241 & 0.171 & 1.29 & 0.023 & 0.248 \\
\hline Received accounts & 0.322 & 0.269 & 1.87 & 0.002 & 0.315 \\
\hline Inventories & 0.289 & 0.239 & 1.35 & 0.002 & 0.246 \\
\hline Depreciation & 0.045 & 0.026 & 0.763 & 0.001 & 0.092 \\
\hline Net earnings & 0.156 & 0.108 & 1.770 & -0.288 & 0.225 \\
\hline Other accruals & -0.04 & 0.006 & 0.959 & -3.95 & 0.503 \\
\hline Real earnings & 40.47 & 11.22 & $579 / 28$ & 0.169 & 91.35 \\
\hline Independence of boards & 0.545 & 0.60 & 1 & 0.2 & 0.181 \\
\hline Ownership concentration & 0.698 & 0.71 & 0.99 & 0.04 & 0.187 \\
\hline Institutional shareholders & 0.723 & 0.82 & 0.99 & 0.01 & 0.265 \\
\hline Management ownership & 0.679 & 0.70 & 0.99 & 0 & 0.19 \\
\hline
\end{tabular}

Regarding the amount of the above table illustrating the descriptive statistics of the research variables, it can be concluded that in all of the variables there is a type of average dispersion which can be inferred from the value of standard deviation. Also, from the gap between mean and median the variable to be symmetrical or asymmetrical can be concluded, and here all of the variables have relative symmetry.

\subsection{First Hypothesis Testing}

This hypothesis tested if the modified earnings regarding the inflation effects, compared with the accounting earnings, have more information content in predicting the future cash flows resulted from the operation. To test this hypothesis, the explanatory power of models one and two should be compared with each other. In the following and in Table 2 the estimation results of these models have been provided.

Table 2. Estimation results for model $1 \& 2$

\begin{tabular}{|c|c|c|c|c|c|c|}
\hline \multirow[b]{2}{*}{ variable } & \multicolumn{3}{|c|}{ First model } & \multicolumn{3}{|c|}{ Second model } \\
\hline & Coefficient & T statistics & Error level & Coefficient & T statistics & Error level \\
\hline Intercept & 0.176 & 3.64 & 0.000 & 0.156 & 3.25 & 0.001 \\
\hline Real earnings & -0.0003 & -01.11 & 0.266 & - & - & - \\
\hline Net earnings & - & - & - & 0.119 & 3.86 & 0.000 \\
\hline Operational cash flow & 0.061 & 1.757 & 0.079 & -0.011 & -0.286 & 0.779 \\
\hline Payable accounts' changes & -0.061 & -2.59 & 0.009 & -0.015 & -0.519 & 0.555 \\
\hline Received accounts' changes & -0.008 & -0.437 & 0.662 & -0.067 & -2.86 & 0.004 \\
\hline Inventories changes & -0.016 & -0.688 & 0.492 & -0.075 & -2.87 & 0.004 \\
\hline Depreciation & -0.059 & -0.885 & 0.376 & -0.055 & 0.819 & 0.413 \\
\hline Other accruals & -0.021 & -1.53 & 0.125 & -0.073 & -4.03 & 0.000 \\
\hline Institutional shareholders & -0.023 & -0.531 & 0.596 & -0.002 & -0.056 & 0.956 \\
\hline Management ownership & -0.011 & -0.31 & 0.757 & -0.002 & -0.045 & 0.964 \\
\hline Independence of boards & 0.009 & 0.632 & 0.718 & 0.016 & 0.595 & 0.552 \\
\hline Ownership concentration & -0.022 & -0.292 & 0.77 & -0.037 & -0.502 & 0.616 \\
\hline Limer F statistics (p-value) & \multicolumn{3}{|c|}{$2.197 \quad(0.000)$} & \multicolumn{3}{|c|}{$2.019 \quad(0.000)$} \\
\hline Haussmann statistics (p-value) & \multicolumn{3}{|c|}{$219.51 \quad(0.000)$} & \multicolumn{3}{|c|}{$198.38 \quad(0.000)$} \\
\hline Model estimation method & \multicolumn{3}{|c|}{ Fixed effects Panel data } & \multicolumn{3}{|c|}{ Fixed effects Panel data } \\
\hline F statistics (p-value) & \multicolumn{3}{|c|}{$6.94 \quad(0.000)$} & \multicolumn{3}{|c|}{$7.074 \quad(0.000)$} \\
\hline Adjusted $\mathrm{R}^{2}$ & \multicolumn{3}{|c|}{0.417} & \multicolumn{3}{|c|}{0.422} \\
\hline Durbin-Watson statistics & \multicolumn{3}{|c|}{2.07} & \multicolumn{3}{|c|}{2.08} \\
\hline Vuong Z statistics & & & 0.418 & $(0.685)$ & & \\
\hline MAPE & \multicolumn{3}{|c|}{$\% 2.61$} & \multicolumn{3}{|c|}{$\% 2.57$} \\
\hline
\end{tabular}


As it is seen in the above table, from the obtained F statistics of Limer and Haussmann for the first model which were equal to 2.2 and 219.5, respectively, and with respect to this point that their error level is equal to zero, it can be concluded that the estimation method of the first model is the panel data with the fixed effects. Also, about the second model, regarding the F statistics of Limer and Haussmann obtained as 2.02 and 198.38, respectively and with respect to this fact that their error level is equal to zero it can be concluded that the estimation method for the second model is also panel data with fixed effects.

Furthermore, regarding the F statistics obtained for both models equal to 6.94 and 7.07 respectively, and their error level equal to 0.000 , it can be stated that at the certainty level of $99 \%$ all of the models have high significance. Again, regarding the obtained modified determining coefficient for both models which is respectively equal to 41.7 and 42.2 , it can be claimed that in the first model the independent variables explain about $41 \%$ of the dependent variables and in the second model about the $42 \%$ of the dependent variables are explained. Moreover, regarding the Durbin-Watson statistics obtained for both models equal to 2.07 and 2.08, respectively, it can be claimed that there is no first-order self-correlation among the models remaining. Now, the obtained results from the research hypotheses are investigated.

As it was mentioned earlier, the aim of this hypothesis is investigating this issue if the modified earnings regarding the inflation effects, compared with the accounting earnings, have more information content in predicting the future cash flows resulted from operations. To compare the models the Wong $\mathrm{Z}$ and comparison of Mean Absolute Percentage Errors of the two models have been used. Regarding the statistics for Wong $Z$ test equal to 0.418 and 0.675 respectively, and with respect to not rejecting the null hypothesis claiming the existence of significant difference between the explanatory powers of two models, it can be concluded that there is no significant difference between the explanatory power of the models one and two. Also, considering the mean absolute percentage errors obtained for both models equal to $2.61 \%$ and $2.57 \%$ respectively, it can be states that there is a trivial difference between the models mean absolute percentage error. Generally, it can be concluded that this hypothesis is not confirmed. According to the investigated hypothesis and the obtained results for it, it can be claimed that the modified accounting earnings with inflation effects, compared with the reported accounting earnings, have identical information content in predicting the future cash flows resulted from the operations.

\subsection{Second Hypothesis Testing}

In this hypothesis it is investigated if the modified earnings, regarding the inflation effects, compared with the accounting earnings, have more information content in predicting the shares' return. This hypothesis is tested followed by two peripheral hypotheses.

\subsubsection{First Peripheral Hypothesis Testing}

In this hypothesis, it is investigated if the modified earnings, regarding the inflation effects, compared with the accounting earnings have more information content in predicting the usual shares' return. To test this hypothesis the explanatory power of the models three and four should be compared with each other. In the following and in Table 3, the results of the estimation for models three and four have been provided. 
Table 3. Estimation results for models $3 \& 4$

\begin{tabular}{|c|c|c|c|c|c|c|}
\hline \multirow[b]{2}{*}{ variable } & \multicolumn{3}{|c|}{ Third model } & \multicolumn{3}{|c|}{ Fourth model } \\
\hline & coefficient & T statistics & Error level & coefficient & T statistics & Level error \\
\hline Intercept & 0.3 & 1.57 & 0.116 & 0.334 & 1.767 & 0.077 \\
\hline Real earnings & -0.0002 & -2.127 & 0.034 & - & - & - \\
\hline Net earnings & - & - & - & -0.026 & -0.202 & 0.84 \\
\hline Operational cash flow & 0.06 & 0.552 & 0.581 & 0.062 & 0.466 & 0.641 \\
\hline Payable accounts' changes & -0.17 & -1.76 & 0.079 & -0.779 & -1.77 & 0.076 \\
\hline Received accounts' changes & 0.052 & 0.619 & 0.536 & 0.054 & 0.512 & 0.608 \\
\hline Inventories changes & -0.135 & -1.235 & 0.217 & 0.139 & -1.105 & 0.269 \\
\hline Depreciation & 0.348 & 1.73 & 0.084 & 0.372 & 1.67 & 0.095 \\
\hline Other accruals & -0.176 & -2.91 & 0.004 & -0.175 & -2.23 & 0.026 \\
\hline Institutional shareholders & -0.107 & -0.825 & 0.409 & 0.112 & 0.886 & 0.376 \\
\hline Management ownership & -0.621 & -4.759 & 0.000 & -0.622 & -4.77 & 0.000 \\
\hline Independence of boards & -0.173 & -1.667 & 0.096 & -0.151 & -1.44 & 0.149 \\
\hline Ownership concentration & 0.581 & 2.728 & 0.007 & 0.783 & 2.59 & 0.009 \\
\hline Limer F stat. (p-value) & \multicolumn{3}{|c|}{$2.142 \quad(0.000)$} & \multicolumn{3}{|c|}{$2.111(0.000)$} \\
\hline Haussmann stat. (p-value) & \multicolumn{3}{|c|}{$22.247 \quad(0.022)$} & \multicolumn{3}{|c|}{$28.456 \quad(0.003)$} \\
\hline Model estimation method & \multicolumn{3}{|c|}{ Panel data with fixed effects } & \multicolumn{3}{|c|}{ Panel data with fixed effects } \\
\hline F statistics (p-value) & \multicolumn{3}{|c|}{$3.275(0.000)$} & \multicolumn{3}{|c|}{$3.327 \quad(0.000)$} \\
\hline Adjusted $\mathrm{R}^{2}$ & \multicolumn{3}{|c|}{0.215} & \multicolumn{3}{|c|}{0.219} \\
\hline Durbin-Watson statistics & \multicolumn{3}{|c|}{2.022} & \multicolumn{3}{|c|}{2.017} \\
\hline Vuong Z statistics & \multirow{2}{*}{\multicolumn{3}{|c|}{0.718}} & $(0.399)$ & & \\
\hline MAPE & & & & \multicolumn{3}{|c|}{$\% 5.8$} \\
\hline
\end{tabular}

As it is seen in the above table, from the obtained F statistics of Limer and Haussmann for the third model which were equal to 2.14 and 22.24, respectively, and with respect to this point that their error level is equal to zero and 0.02 , it can be concluded that the estimation method of the third model is the panel data with the fixed effects. Also, about the fourth model, regarding the F statistics of Limer and Haussmann obtained as 2.11 and 28.45, respectively and with respect to this fact that their error level is equal to zero it can be concluded that the estimation method for the fourth model is also panel data with fixed effects.

Furthermore, regarding the F statistics obtained for both models equal to 3.27 and 3.32 respectively, and their error level equal to 0.000 , it can be stated that at the certainty level of $99 \%$ all of the models have high significance. Again, regarding the obtained modified determining coefficient for both models which is respectively equal to 21.5 and 21.9 , it can be claimed that in the third model the independent variables explain about $21.5 \%$ of the dependent variables and in the fourth model about the $21.9 \%$ of the dependent variables are explained. Moreover, regarding the Durbin-Watson statistics obtained for both models equal to 2.022 and 2.017, respectively, it can be claimed that there is no first-order self-correlation among the models remaining. Now, the obtained results from the research hypotheses are investigated.

As it was mentioned earlier, the aim of this hypothesis is investigating this issue if the modified earnings regarding the inflation effects, compared with the accounting earnings, have more information content in predicting the usual shares' return. To compare the models the Wong Z and comparison of Mean Absolute Percentage Errors of the two models have been used. Regarding the statistics for vuong $Z$ test equal to 0.718 and 0.399 respectively, and with respect to not rejecting the null hypothesis claiming the existence of significant difference between the explanatory powers of two models, it can be concluded that there is no significant difference between the explanatory power of the models three and four. Also, considering the mean absolute percentage errors obtained for both models equal to $5.76 \%$ and $5.8 \%$ respectively, it can be states that there is a trivial difference between the models mean absolute percentage error. Generally, it can be concluded that this hypothesis is not confirmed. According to the investigated hypothesis and the obtained results for it, it can be claimed that the modified accounting earnings with inflation effects, compared with the reported accounting earnings, have identical information content in predicting the usual shares' return. 


\subsubsection{Second Peripheral Hypothesis Testing}

In this hypothesis, it is investigated if the modified earnings, regarding the inflation effects, compared with the accounting earnings have more information content in predicting the unusual shares' return. To test this hypothesis the explanatory power of the models three and four should be compared with each other. In the following and in Table 4, the results of the estimation for models five and six have been provided.

Table 4. Models 5\&6 estimation results

\begin{tabular}{|c|c|c|c|c|c|c|}
\hline \multirow[b]{2}{*}{ variable } & \multicolumn{3}{|c|}{ Fifth model } & \multicolumn{3}{|c|}{ Sixth model } \\
\hline & coefficient & T statistics & Error level & coefficient & T statistics & Error level \\
\hline Intercept & 0.859 & 2.648 & 0.008 & 0.883 & 1.742 & 0.082 \\
\hline Real earnings & -0.002 & -15.01 & 0.000 & - & - & - \\
\hline Net earnings & - & - & - & -0.163 & -0.518 & 0.604 \\
\hline Operational cash flow & 0.516 & 2.99 & 0.003 & 0.507 & 1.82 & 0.068 \\
\hline Payable accounts' changes & -0.588 & -3.37 & 0.001 & -0.524 & -2.02 & 0.044 \\
\hline Received accounts' changes & 0.399 & 2.91 & 0.004 & 0.227 & 1.05 & 0.293 \\
\hline Inventories changes & 0.476 & 2.76 & 0.006 & 0.116 & 0.445 & 0.656 \\
\hline Depreciation & 1.586 & 3.46 & 0.000 & 1.74 & 2.81 & 0.005 \\
\hline Other accruals & 0.215 & 2.09 & 0.036 & -0.019 & -0.119 & 0.905 \\
\hline Institutional shareholders & -0.586 & -2.15 & 0.032 & -0.699 & -2.06 & 0.039 \\
\hline Management ownership & -0.633 & -2.77 & 0.006 & -0.967 & -2.92 & 0.003 \\
\hline Independence of boards & -0.387 & -2.108 & 0.035 & -0.163 & -0.658 & 0.511 \\
\hline Ownership concentration & 0.278 & 0.546 & 0.586 & 0.417 & 0.543 & 0.587 \\
\hline Limer F statistics ( $\mathrm{p}$-value) & \multicolumn{3}{|c|}{$1.696 \quad(0.000)$} & \multicolumn{3}{|c|}{$1.539 \quad(0.000)$} \\
\hline Haussmann statistics (p-value) & \multicolumn{3}{|c|}{$29.132 \quad(0.002)$} & \multicolumn{3}{|c|}{$29.765 \quad(0.002)$} \\
\hline Model estimation method & \multicolumn{3}{|c|}{ Panel data with fixed effects } & \multicolumn{3}{|c|}{ Panel data with fixed effects } \\
\hline F statistics (p-value) & \multicolumn{3}{|c|}{$3.152 \quad(0.000)$} & \multicolumn{3}{|c|}{$1.636 \quad(0.000)$} \\
\hline Adjusted $\mathrm{R}^{2}$ & \multicolumn{3}{|c|}{0.206} & \multicolumn{3}{|c|}{0.071} \\
\hline Durbin-Watson statistics & \multicolumn{3}{|c|}{1.912} & \multicolumn{3}{|c|}{1.946} \\
\hline Vuong $\mathrm{Z}$ statistics & \multicolumn{6}{|c|}{0.778} \\
\hline MAPE & \multicolumn{3}{|c|}{$\% 5.67$} & \multicolumn{3}{|c|}{$\% 6.02$} \\
\hline
\end{tabular}

As it is observed in the Table 4, from the obtained F statistics of Limer and Haussmann for the third model which were equal to 1.69 and 29.13, respectively, and with respect to this point that their error level is equal to zero, it can be concluded that the estimation method of the fifth model is the panel data with the fixed effects. Also, about the sixth model, regarding the F statistics of Limer and Haussmann obtained as 1.54 and 29.76, respectively and with respect to this fact that their error level is equal to zero it can be concluded that the estimation method for the sixth model is also panel data with fixed effects.

Moreover, regarding the F statistics obtained for both models equal to 3.15 and 1.64 respectively, and their error level equal to 0.000 , it can be stated that at the certainty level of $99 \%$ all of the models have high significance. Also, regarding the obtained modified determining coefficient for both models which is respectively equal to 20.6 and 7.1, it can be claimed that in the fifth model the independent variables explain about $20 \%$ of the dependent variables and in the fourth model about the $7 \%$ of the dependent variables are explained. In addition, regarding the Durbin-Watson statistics obtained for both models equal to 1.91 and 1.94, respectively, it can be claimed that there is no first-order self-correlation among the models remaining. Now, the obtained results from the research hypotheses are investigated.

As it was expressed earlier, the aim of this hypothesis is investigating this issue if the modified earnings regarding the inflation effects, compared with the accounting earnings, have more information content in predicting the unusual shares' return. To compare the models the Wong Z and comparison of Mean Absolute Percentage Errors of the two models have been used. Regarding the statistics for vuong $\mathrm{Z}$ test equal to 0.778 and 0.376 respectively, and with 
respect to not rejecting the null hypothesis claiming the existence of significant difference between the explanatory powers of two models, it can be concluded that there is no significant difference between the explanatory power of the models fife and six. Also, considering the mean absolute percentage errors obtained for both models equal to $5.67 \%$ and $6.02 \%$ respectively, it can be states that there is a trivial difference between the models mean absolute percentage error. Generally, it can be concluded that this hypothesis is not confirmed. According to the investigated hypothesis and the obtained results for it, it can be claimed that the modified accounting earnings with inflation effects, compared with the reported accounting earnings, have identical information content in predicting the unusual shares' return.

\section{Discussion and Conclusion}

As it was expressed before, the aim of this study was to investigate the effect of inflation disclosure on improving the information content of the financial reporting of accepted companies in Tehran securities exchange. To investigate this issue, three hypotheses were provided. To this aim, data related to 120 companies accepted in Tehran securities exchange was analyzed during the time period of 2002 to 2012. The results in general term showed that the inflation does not have a significant effect on information content of the financial reporting of the companies in Tehran securities exchange. The results of the first hypothesis also showed specifically that there is not a significant difference between the information content of the modified accounting earnings and the inflation effects, compared with the reported accounting earnings in predicting the operational cash flow. The results of the second hypothesis also showed that there is not a significant difference between the information content of the modified accounting earnings and the inflation effects, compared with the reported accounting earnings in predicting the unusual return of the shares. According to the obtained results it can be noted that the existed inflation has a very complicated structure in economy which for the effects all of its elements in different structures of the market should be investigated and applying a fixed rate for inflation modifications cannot merely be useful for investigating its effects on a specific case like information content of the financial reporting. For example, this case can be noted that the inflation expectations of various individuals can be different and this issue will challenge the analysis of inflation expectations and their effects on the individuals and various groups' decision making, and causes the lack of prediction about the inflation effects on the earnings growth correctly. This issue leads to decreasing the revenues of the shares in an interval in which the inflation is high, and increasing them when the inflation is low. In fact, in spite of undeniable effects this phenomenon can have on the efficiency of the content of the financial reporting of the companies, the obtained result does not confirm such an issue.

On the other hand, the possible reasons for the obtained results can be the inefficiency of the investment market of the country which can be the very important and restrictive of the lack of using the inflation effects on efficiency in decision makings for investors. Also, among other reasons the complexities relevant to the investigation of inflation effects on different analyses about the current and future status of the companies can be noted which in this study are used. This issue itself can show the more restrictive application of identification of the modified earnings and losses based on the inflation in decision making of the investors existed in market.

Totally, the obtained results in this study are in accordance with the results of other research conducted on this issue like Yosef and Lev (1983), Samuelson and Mordak (1985), Gregory et al (2005), Shah Rezaei (2003), Nikbakht and Tanani (2008), Botshekan and Salmani (2010).

\section{Suggestions}

Regarding this fact that the dominant economy over our country is an inflation economy, and on the other hand the professional organizations including the Audit Organization which is responsible for developing the accounting standards in Iran, has not done anything yet to develop and prescribe the financial reporting disclosure based on the prices indices; accordingly, it is expected that the Audit Organization, specifically the Accounting Standards Committee of the Securities Exchange of Tehran, (as the organizations which are responsible for increasing the financial reporting quality and information clarification) can be aware of the inflation effects of the financial reporting with the necessity of developing the standards, creating the procedures, instructions, and disclosure requirements.

Moreover, the Ministry of Economic and finance which is responsible for levy based on the companies' performance results, can determine the amount of companies' real taxable incomes to see how much of their performance results are from the economic conditions dominant on the companies by considering the business units' purchasing power. Levy in a fair way can contribute to the government in executing the macro-economic policies and people's welfare in addition to encouraging the taxpayers in paying the taxes and keeping the investment as well as the power of the private section. 


\section{References}

Adel M. Novin. (1982). An Empirical Investigation, p.70.

Anandarajan, A, Hasan, I. Isik, I., \& McCarthy, C. (2006). The role of earnings and book values in pricing stocks: evidence from Turkey. Advances in International Accounting, 19, 59-89. http://dx.doi.org/10.1016/S0897-3660(06)19003-0

Ashton, D., Peasnell, K., \& Wang, P. (2010). Residual Income Valuation Models and Inflation.

Auditing Standards Committee of Iran, Audit Organization.

Bar-Yosef, S., \& B. Lev. (1983). Historical cost earnings versus inflation-adjusted earnings in the dividend decision. Financial Analysts Journal, 39(2), 41-50. http://dx.doi.org/10.2469/faj.v39.n2.41

Benderly, Jason, \& Swick, Burton. (1985, December). Inflation, Real Balance, OUTPUT, and Real Stock Returns. Americal Economic Review, 1115-1122.

Bhatnagar and Kumar. (2012, November). Impact of Inflation in Financial Reporting (A Case Study of Inflation and Financial Reporting in developing Economy). Spectrum: A Journal of Multidisciplinary Research, 1(8).

Boudoukh, Jacob, \& Richardson, Matthew. (1993, March). Stock Returns and Inflation: A Long-Horizon Perspective. American, Economic Review, 1346-1355.

Dastgir, Mohsen. (1867). Accounting for inflation. Accountant Magazine, (30).

Dechow, P. M., R. G. Sloan, \& A. Sweeney. (1995). Detecting earnings management. The Accounting Review, 70(2), 193-225.

Eldons, Hendriksen. (1990). Accounting theory. Home Wood, I11, Richard O Irwin, Inc.

Ernest and Ernest. (1975). Price level accounting: Financial Reporting Development.

Fama E.F. (1981). Stock Returns, Real Activity, Inflation and Money. American Economic Review, 71(4), 545-565.

Garmendia D. P. (2010). Inflation, Stock Prices and Real Earnings in Emerging Markets: Friedman Was Right. September 2010. Retrieved from http://www.econ.upf.edu

Graham, C., \& Fred. (1995). Real Stock Return and Monetary Policy. Applied Financial Economics, (6), 29-35.

Gregory, A., Saleh, W., \& Tucker, J. (2005, April/May). A UK test of an inflation-adjusted Ohlson model. Journal of Business Finance and Accounting, 487-534. http://dx.doi.org/10.1111/j.0306-686X.2005.00602.x

Gultekin, N. Bulent. (1983, March). Stock Market Returns and Inflation: Evidence from Other Counties. The Journal of Finance, 49-65. http://dx.doi.org/10.1111/j.1540-6261.1983.tb03625.x

Harry Wolk.et al. (1992). Accounting Theory: A Conceptual and Institutional Approach, p.169.

Hernandez, Leonardo. (1990, December). Inflation Y Retorno Bursatil, Una Investigation Empirical: Chile 1960-1983. Cuadernos-De-Econmia, 381-406.

Kirkulak, B., \& Cagnur K. Balsari. (2009). Value relevance of inflation adjusted equity and income. The International Journal of Accounting, 44, 363-377. http://dx.doi.org/10.1016/j.intacc.2009.09.007

Konchitchki and Landsman. (2010). Cost of capital and earnings transparency. Working paper, Stanford University.

Konchitchki, Y. (2009). Inflation and Nominal Financial Reporting: Implications for Performance and Stock Prices.

Paul Rosenfield. (1975). Relevance and Interpretability. The Journal of Accountancy, 52-57.

Royaei, Ramezanali. (1993). Inflation accounting and Development of accounting in Iran. Accountant Magazine, $(101,102)$.

Saghfi Ali. (1996). The use of control systems analysis and cost deviations. Accounting Review. 